\title{
A multi-dimensional treatment of quantification in extraordinary English
}

\author{
Paul Dekker
}

Published online: 9 July 2008

(C) The Author(s) 2008

\begin{abstract}
In this paper I revive two important formal approaches to the interpretation of natural language, that of Montague and that of Karttunen and Peters. Armed with insights from dynamic semantics (Heim, Krifka) the two turn out to stand up against age-old criticisms in an orthodox fashion. The plan is mainly methodological, as I only want to illustrate the technical feasibility of the revived proposals. Even so, there are illuminating and welcome empirical consequences on the subject of scope islands (as discussed by Abusch and Kratzer, among many others), as well as unintended theoretical implications in the contextualist debate (Grice, Recanati, Simons, Stanley, and many others again).
\end{abstract}

Keywords Semantics · Pragmatics · Quantification · Dynamic interpretation $\cdot$ Scope islands

\section{Introduction}

In this paper I present a three-dimensional architecture for the interpretation of a fragment of natural language dealing with the dynamics of quantification. The starting point is Montague's proper treatment, inspired by the work of Frege, Russell, Tarski and many others, and its arguably 'pragmatic', two-dimensional, extension given by Karttunen and Peters, and again many others. The main purpose is to show that the basic ideas of these authors are still viable, that they can be made to stand up against age-old criticisms, and that it is productive to do so.

The major contribution consists in showing the technical feasibility of the mentioned approaches. I will not take time and opportunity to delve into the 
intricate empirical details of generalized and dynamic quantification. ${ }^{1}$ Nor will I engage in deep discussions about the aims and tasks of a theory of natural language interpretation. I have chosen to present a three-dimensional architecture of interpretation; from a logical perspective the reason is this. Cases that count, formally speaking, are 'zero', 'one' and 'more'; presenting a three- instead of a twodimensional approach gives all the clues towards an $n$-dimensional analysis, with $n>1 .^{2}$

Major achievements and results have been made in the study of quantifying expressions in natural and formal languages over the last forty years or so. None of these will be disputed here. Some, more programmatic proposals have been made arguing that such studies require a representational, or dynamic, or constructive, theory of meaning (Kamp, Groenendijk and Stokhof, Ranta and Hintikka). I will not take a stand on these issues, except that one need not be committed to either in order to pursue a viable theory of interpretation. The goal of this paper is to lay out, discuss and defend a multi-dimensional architecture for the interpretation and use of quantifying expressions in natural language, which conservatively builds upon the Montagovian paradigm and constructively takes pragmatic insights into account. The architecture has been inspired, but not dictated, by insights from dynamic semantics. I take it that dynamic semantics does not provide an old or novel theory of meaning, but an approach to interpretation that takes systematic aspects of use into account.

I proceed as follows. First, in Sect. 2, I present a proper extension of predicate logic with pronouns $(P L A)$ and a multi-dimensional device to deal with what are called presuppositions. In Sect. 3 I introduce dynamic generalized quantifiers in this framework, as a proof of concept. In the formulation given, I show how both backward- and forward-looking aspects of certain quantifiers can be accounted for, although it will be evident that many quantifiers must, and can, be dealt with in slightly different ways. Section 4 presents a surprising benefit of our endeavour: the puzzling escapist behavior of indefinite expressions on scope islands turns out to be no mystery after all. They systematically turn out to behave like other terms. In Sect. 5 I discuss some theoretical consequences of the approach taken in this paper.

\section{Pronouns and presuppositions}

In this section I briefly introduce a first order system of interpretation which deals with basic aspects of pronominal anaphora and presupposition. The treatment of pronouns consists in, I believe, a most minimal extension of first order predicate logic. The language of Predicate Logic with Anaphora $(P L A)$ is that of first order

\footnotetext{
${ }^{1}$ Such would require at least a monograph of its own, if only to discuss all the valuable things that have been written on the subject over the past twenty years or so. This provides a more important reason to present an architecture along the lines of this paper: all these scattered ideas, observations and attempts at formalization, however valuable, make no sense in the long run if not embedded in one general framework.
}

${ }^{2}$ Which is to say, a two-dimensional approach runs the risk of being deemed ad hoc. 
predicate logic, extended with a category of pronouns, terms which refer back to elements introduced in previous discourse. 'Presuppositions', for lack of a better term, are dealt with in the multi-dimensional spirit of Karttunen and Peters. As will be seen by the end of this paper, the treatment of presupposition is, by and large, empirically equivalent with the most successful procedural treatment in the $A B$ theory of Rob van der Sandt and Bart Geurts. However, while the AB theory deals with the triggering and resolution of presuppositions at a representational level, it leaves the question about the intermediate semantic entities unanswered. In the system presented in this section, pronominal and presuppositional expressions do have their own interpretation, which, like I said, is one that properly extends (not changes) the familiar interpretation associated with them.

Although the system of PLA has grown out of the tradition of discourse representation and dynamic interpretation (cf., Kamp and Reyle 1993; Groenendijk and Stokhof 1991) it tries to deviate from a classical semantics only minimally (cf., Dekker 2004a). It is mainly inspired by (Stalnaker 1998) and formally develops the idea that terms, including indefinite noun phrases, can be used with referential intentions, and that anaphoric pronouns can be coreferential with these terms by picking up individuals which may satisfy these intentions.

The language of $P L A$ is like that of first order predicate logic except for the fact that it also contains a category of pronouns $P=\left\{\mathrm{p}_{1}, \mathrm{p}_{2}, \ldots\right\}$. For ease of exposition, I focus on a minimal language which is built up from variables, names, pronouns, $=$ and $n$-ary relation expressions, by means of negation $\neg$, existential quantification $\exists x$ and conjunction $\wedge$. As is usual, I use existentially quantified expressions to model the interpretation of indefinite noun phrases in natural language. The interpretation of conditional sentences, however limited, is modeled using material implication $\rightarrow$, defined by $(\phi \rightarrow \psi)=\neg(\phi \wedge \neg \psi)$.

The semantics of $P L A$ is spelled out by means of a satisfaction relation $\models$, which may hold between, on the one hand, an ordinary first order model $M$ with domain $E$, an ordinary variable assignment $g$, and a sequence of individuals $e$, and, on the other hand, a formula $\phi$ of the PLA language. The sequences of individuals $e$ are the possible referents of terms (definite, indefinite and pronominal) in $\phi$. Besides the use of these possible 'witnesses', the only deviation from a classical semantics is that I also take into account what is referred to as $n(\phi)$, the number of (surface) existentials in $\phi$. Satisfaction is defined as follows:

\section{Definition 1 (Satisfaction in PLA)}

- $[t]_{M, g, e}=M(c)$ if $t \equiv c \quad[t]_{M, g, e}=g(x)$ if $t \equiv x \quad[t]_{M, g, e}=e_{i}$ if $t \equiv \mathrm{p}_{i}$

- $M, g, e \models R t_{1} \ldots t_{m} \quad$ iff $\left\langle\left[t_{1}\right]_{M, g, e}, \ldots,\left[t_{m}\right]_{M, g, e}\right\rangle \in M(R)$

$M, g, e \models \neg \phi \quad$ iff $M, g, c e \models \phi$ for no $c \in E^{n(\phi)}$

$M, g, d c e \models \exists x \phi \quad$ iff $M, g[x / d], c e \models \phi$ for $d \in E$

$M, g$, ace $\models \phi \wedge \psi \quad$ iff $M, g, c e \models \phi$ and $M, g, a c e \models \psi$, with $a \in E^{n(\psi)}$

The crucial clauses are that of existential quantification and conjunction. If a sequence $c e$ satisfies $\phi$ under an assignment $g[x / d]$ mapping $x$ to $d$, then $d c e$, the 
sequence $c e$ with $d$ added as a witness, satisfies $\exists x \phi$ under $g$. Except for the addition of the witness, this clause is totally standard.

The 'dynamics of interpretation' is captured by our notion of conjunction, which models nothing more than the fact that if a conjunction is actually used, the first conjunct literally precedes the second. If a sequence $c e$ satisfies $\phi$, where $c$ is a sequence of witnesses for terms in $\phi$ relative to $e$, and if ace satisfies $\psi$, where $a$ is a sequence of witnesses for terms in $\psi$ relative to $c e$, then the whole sequence ace also satisfies the conjunction of $\phi$ and $\psi$. The difference with a classical notion is again the use of witnesses only.

Let me explain a point about notation. In most cases, the sequences of witnesses of indefinites are cut up so as to correspond to the direct constituents of a formula, plus a tail $e$ which is supposed to supply previously introduced sequences of witnesses which could be picked up by pronouns. Thus, in the case of the conjunction $\phi \wedge \psi$, I use the sequence ace, where the sequence $a$ represents the possible contribution of $\psi, c$ that of $\phi$, and $e$ relates to previous discourse. ${ }^{3}$ Observe that existentials and pronouns are quite similar in $P L A$, for:

\section{Observation 1 (Indefinites and pronouns)}

- $M, g, d e \models \exists x F x \quad$ iff $M, g, e^{\prime} \models F \mathrm{p}_{1}$ where $d e=e^{\prime}$ $M, g, b d e \models \exists x \exists y R x y \quad$ iff $M, g, e^{\prime} \models R \mathrm{p}_{1} \mathrm{p}_{2}$ where $b d e=e^{\prime}$

The difference between the two types of terms resides in the way they are taken up in various configurations. Indefinites can be seen to introduce 'new' referents, whereas pronouns refer back to 'old' ones. Besides, indefinites are existentially quantified under a negation, whereas pronouns, of course, are not. Notice that pronouns and variables have a complementary distribution. Variables can only be bound by quantifiers in whose scope they find themselves; pronouns, however, do not 'see' these quantifiers, and only refer back to witnesses which pop up after an existential formula has been closed. ${ }^{4}$

The use of witnesses in PLA enables a straightforward account of crosssentential anaphoric relationships. Basic results of discourse representation theory and dynamic semantics are captured, as the reader can verify by checking the validity of the following equivalences:

\section{Observation 2 (Anaphoric relations)}

- $\exists x(D x \wedge \exists y(P y \wedge F x y)) \wedge L \mathrm{p}_{1} \mathrm{p}_{2} \Leftrightarrow \exists x(D x \wedge \exists y(P y \wedge F x y \wedge L x y))$

- $\exists x(F x \wedge \exists y(D y \wedge O x y)) \rightarrow B \mathrm{p}_{1} \mathrm{p}_{2} \Leftrightarrow \forall x(F x \rightarrow \forall y((D y \wedge O x y) \rightarrow B x y))$

Indeed, these formal equivalences correlate to the intuitive equivalence of the following examples, with our apologies for the worn-out second one:

(1) A diver found a pearl but she lost it again.

A diver lost a pearl she just found.

\footnotetext{
${ }^{3}$ With this notation convention, reference to $n(\phi)$ and $n(\psi)$ can be suppressed throughout.

4 Alastair Butler has pointed out interesting consequences of this view.
} 
(2) If a farmer owns a donkey he beats it.

Every farmer beats every donkey he owns.

PLA has been developed as a (negative) answer to the claim that a semantic account of anaphoric dependencies requires a representational or dynamic notion of meaning. Like I said, our semantics extends a classical satisfaction relation with witnesses only, and the dynamics is located in its (asymmetric) notion of conjunction. Besides, this use of witnesses has been given independent motivation in (Dekker 2004a) which in its turn is inspired almost entirely by (Kamp 1990; van Rooy 1997a; Stalnaker 1998). The underlying idea is that indefinite terms, like other terms, are generally used with referential intentions. A speaker may use an indefinite because the identity of the intended referent is not relevant, or because he does not have adequate means to identify that referent. However, also in the latter case it is assumed that there is a true (possibly unknown) answer to the question which individual it is about, in order for subsequent pronouns not to be opaque.

Formally PLA fleshes out the assumption that indefinite descriptions are used to introduce possible witnesses, but it does not do justice to the fact that the descriptive material by means of which they do so has what seems to be a special informational status. Although one can deny:

(3) Yesterday some student wanted to hear my ideas about negative polarity.

by means of (4) and (5):

(4) No, nobody wanted to know anything from you yesterday.

(5) No, she only wanted to impose herself on you.

it seems awkward to reply with:

(6) No, she is not a student any longer.

If something like the latter is what is intended, a better reply would be:

(7) Well, maybe she indeed wanted to hear your ideas (something I doubt by the way), but she is not a student any longer.

Cutting things short, while definite and indefinite noun phrases, and pronouns, share important semantic characteristics, they behave significantly different when it comes to their actual interpretation.

With the architecture proposed here I revive the two-dimensional approach from (Karttunen and Peters 1975; Karttunen and Peters 1979). ${ }^{5}$ A presuppositional and an assertional dimension can be incorporated in PLA by explicitly distinguishing presupposition satisfaction $\models^{p}$ and assertion satisfaction $\models^{a}$. Simple satisfaction $\models$ is defined by means of the intersection of $\models^{p}$ and $\models^{a}$, which implies that the very

\footnotetext{
${ }^{5}$ Or 'implicature' and 'extension', as Karttunen and Peters had it. I use the term 'presupposition' with the proviso that it is employed as a technical term only, without any intuitive implicatures.
} 
same sequences will be relevant in both presupposition and assertion. As a consequence, these sequences allow us to state interdependencies.

Just to get things started in a most obvious way, let's render $\models^{a}$ as $\models$ for any formula $\phi$ in the language of $P L A$, and $\models^{p}$ as trivially true. (The core language of $P L A$ expresses only assertions, and conveys no presuppositions.) Presuppositions may enter the stage along with a presupposition device $\langle\phi\rangle$, much in the style of (Beaver 1995). ${ }^{6}$ Our satisfaction semantics then can be adapted in the following way. (1n the following definition ${ }^{x}$ is a variable for $p$ (presupposition) and ${ }^{a}$ (assertion), respectively.)

\section{Definition 2 (Presupposition in PLA)}

- $M, g$, ace $\models^{p}\langle\phi\rangle \psi \quad$ iff $M, g, c e \models \phi$ and $M, g$, ace $\models^{p} \psi$

$M, g$, ace $\models^{a}\langle\phi\rangle \psi \quad$ iff $M, g$, ace $\models^{a} \psi$

- $M, g, e \models^{p} \neg \phi \quad$ iff $\exists c: M, g, c e \models^{p} \phi$

$M, g, e \models^{a} \neg \phi \quad$ iff $\neg \exists c: M, g, c e \models^{a} \phi$

- $M, g, d c e \models^{x} \exists x \phi \quad$ iff $M, g[x / d], c e \models^{x} \phi$

- $M, g$, ace $\models^{x} \phi \wedge \psi \quad$ iff $M, g, c e \models^{x} \phi$ and $M, g$, ace $\models^{x} \psi$

If sequence $a$ satisfies the presuppositions of $\psi$ relative to $c e$, and if $c$ satisfies $\phi$ relative to $e$, then ace satisfies the presupposition of $\psi$ upon the presupposition that $\phi$. What is asserted is, of course, what is asserted by $\psi$, As is fairly usual, a negation preserves the presuppositions of a negated formula, and negates its contents. An existentially quantified formula presupposes and asserts what the embedded formula presupposes and asserts, with a suitable switch of the witness from the sequence to the assignment. Presupposition and assertion distribute over a conjunction.

It should be emphasized that the above definitions do not correspond one to one to constituents found in the syntactic analysis of natural language. The aim was giving the underlying fundaments of an architecture which enables one to model the interpretation of concrete utterances. For one thing, a negation, as defined here, does not give us presupposed witnesses, as one might want in certain cases. For another, there are various alternative (and viable) ways in which one can compose the interpretation of two conjuncts. Some alternatives will be mentioned below, as well as the impact of having a possibility to choose.

Some people think that Karttunen and Peters' system suffers from a serious gap, which, by the way, they themselves have addressed in the first note to their paper. However, in the very same note, Karttunen and Peters already envisaged the possibility of stopping this gap, and ironically, van der Sandt and Geurts have filled it quite a while ago. Consider:

(8) Someone managed to succeed George V on the throne of England.

According to the theory of (Karttunen and Peters 1979), an utterance of this sentence presupposes that someone had a hard time trying to succeed George V, and

\footnotetext{
${ }^{6}$ Please note that I will do away with this presupposition device in the next section, where presuppositions are directly encoded in the semantics of their triggers.
} 
asserts that someone eventually succeeded him. The problem for this theory then is (or was) that it doesn't (didn't) account for the intuition that the presupposition and the assertion relate to one and the same individual. So all that is required is to account for semantic dependencies between meaningful items, be they assertions or presuppositions - and this is something one can do in all versions of discourse representation theory and dynamic semantics. ${ }^{7}$ One and the same witness can be said to satisfy both the presupposition and the assertion of this sentence. Schematically:

\section{Observation 3 (Solving a management problem (1))}

- $M, g, d e \models^{p} \exists x(\langle T R Y x s\rangle S U C C x s) \quad$ iff $d$ tries $s$

- $M, g, d e \models^{a} \exists x(\langle T R Y x s\rangle$ SUCCXs) $\quad$ iff $d$ succeeds with $s$

An utterance of (8) thus can be said to presuppose that someone had succession difficulties, and to assert that he (that very same person) eventually succeeded. (As argued by Karttunen and Peters themselves, the sentence is judged odd, because the witness for the assertion (the successor) had no problems whatever succeeding George V.) Since the assertion of (8) is satisfied, the negation of the sentence is not:

(9) No one managed to succeed George V on the throne of England.

For observe:

\section{Observation 4 (Solving a management problem (2))}

- $M, g, e \models^{p} \neg \exists x(\langle T R Y x s\rangle S U C C x s)$ iff somebody tries $s$

- $M, g, e \models^{a} \neg \exists x(\langle T R Y x s\rangle S U C C x s)$ iff nobody succeeds with $s$

Even though the actual successor of George $\mathrm{V}$ did not have a hard job with this, he did succeed George V, and this suffices to make (9) false. One might object that this is too strong, and take (9) to assert that none of those who tried hard did succeed George V. I agree that such an interpretation is possible.

Before going along, and turn to more involved constructions, let us reflect on the possibility of combining structured information in alternative ways, as discourse and context seem to require. I would like to conclude this section with some tentative alternatives for conjoining information, but similar remarks may apply to any other connective or operator.

Notice that the presupposition of one conjunct may be taken to be dependent on the assertoric impact of another. Consider:

Jones bought a house in France.

The previous owner has moved to Hungary.

\footnotetext{
${ }^{7}$ I have made this suggestion earlier (cf., e.g., Dekker 1998) and a solution along these lines has already been anticipated by Karttunen and Peters themselves: "What our rules as stated lack is any way of linking the choice of a person who is implicated to have difficulty to the choice of a person who is asserted to have succeeded. We expect that this deficiency will be remedied through further research, but we note here that this task is not a trivial one.' (Karttunen and Peters 1979, p. 53). I believe the task is trivial but working it out has shown to be not.
} 
A conjunction of these two utterances can be said to presuppose that there is some person $d$ known under the name of 'Jones' and, that it introduces a house $h$ he bought in France. What should one say about the presupposition, from the second utterance, that $h$ has a definite owner $o$, and the assertion that $o$ moved to Hungary? As suggested above, we can simply collect the relevant presuppositions, contributions and assertions. Doing so, an utterance of (10) presupposes that $d$ is Jones and that $o$ is the owner of $h$, and it asserts that $h$ is a house $d$ bought and that $o$ moved to Hungary. It would be more appropriate to make the second utterance functionally dependent upon that of the first, so that the owner would depend on the house Jones bought. We could also turn the assertive impact of the first utterance into a presupposition of the second, which actually seems to be what (Stalnaker 1978) proposed. Indeed, we can conceive of many ways to put the informational pieces together. Pending further considerations about contexts, I deem these solutions all acceptable, and I do not want to decide between them here. The main point is that we have an architecture which can accommodate all such interpretations.

\section{Terms and quantifiers}

It is certainly not common knowledge, but equally certainly it is agreed upon by those interested in the subject, that definite noun phrases (including proper names and pronouns) and indefinite noun phrases make similar but different types of contributions to the actual interpretation of sentences, one that is different from other predicative (assumed focal) material. ${ }^{8}$ Hans Kamp and Irene Heim's seminal work is to be credited first in this respect, although, to mention just a few, Chastain, Geach, Kripke, Donnellan, Evans, and Neale express similar opinions (in the philosophical tradition), as do Reinhart, Abusch, von Heusinger, Kratzer, Winter (in an, arguably, more linguistic tradition). ${ }^{9}$ Van der Sandt, Geurts, and Kamp (in joint work with Roßdeutscher and Bende Farkas) have given a formal, and quite attractive, implementation of these insights in the procedural framework of $D R T$. But despite numerous attempts to the contrary (Beaver, Krifka, van Rooij, Breheny, Jäger) no convincing interpretative semantics for this procedure has been offered so far. This section is intended to fill this gap, while it presents a minimal (multi-dimensional) interpretation of terms, and, because it is really necessary by now, an architecture for the interpretation of generalized quantifiers which adequately deals with these terms.

Every now and then it will be seen that, apart from the tools required to do our job, everything is like it used to be. Terms denote individuals, nouns and verbs denote sets of individuals, quantifiers denote sets of sets of individuals, etc. The main ideas to be substantiated are these. I build upon the Montagovian interpretation algebra from the seventies, employing the tools and machinery from generalized

\footnotetext{
${ }^{8}$ We ought to include Wh-phrases, which behave like terms, semantically, but whose conditions of use are different again.

${ }^{9}$ A three-way distinction in semantic interpretation is also (remotely) similar in spirit to Vallduví's three partite distinction between three types of sentential constituents. First level presuppositions may count as given, and indefinite contributions and assertions as new. Furthermore, the presuppositions and contributions made by terms can be conceived of as the ground, and the assertion as the focus.
} 
quantifier theory (also from the seventies), and reformulate it in a multi-dimensional framework (also from the seventies) using the discourse theoretical insights deriving from the eighties and the nineties. The most important ideas to be implemented are that indefinite noun phrases come with referential intentions, and introduce discourse referents, but that they are not presuppositional in the way that definites and pronouns are. Typically, definites do not get bound (existentially closed) by other operators, whereas indefinites do, or at least seem to.

The ideas about the interpretation of terms and quantified noun phrases is fleshed out in the interpretation of a fragment of natural language in three dimensions, which are labelled 'presupposition', 'contribution' and 'assertion', respectively. (Again, these terms are meant to be technical terms only.) We have terms (proper names, pronouns, definite and indefinite descriptions) and generalized quantifiers. Descriptions and quantifiers are obtained by combining a determiner with a common noun phrase (a one-place predicate or a formula abstracted over). Together with a verb phrase (also a one-place predicate or $\lambda$-term), they make up a sentence or formula. Thus, for instance, "gives some book to Mary" will be rendered as $\lambda x M A R Y(\lambda y S O M E(\lambda z B O O K z)(\lambda z G I V E x y z))$. Basic predicates like BOOK and GIVE are interpreted like the corresponding relational constants in PLA: without any presupposition or contribution they denote sets of individuals (books) and sets of triples of entities which stand in the give relation; and for any expression $E$, let's define $\llbracket E \rrbracket_{M, g, c e}$, the interpretation of $E$ relative to $M, g$ and $c e$ as the intersection of $\llbracket E \rrbracket_{M, g, c e}^{p}, \llbracket E \rrbracket_{M, g, c e}^{c}$ and $\llbracket E \rrbracket_{M, g, c e}^{a}$, the presupposition of $E$, the contribution of $E$, and the assertion or denotation of $E$, respectively. As the reader will see, all three are given in the same, familiar, type, although they are conditional upon sequences of witnesses. For a compositional interpretation of terms (and that of quantifiers) I have to introduce a notion of first order abstraction:

- $\llbracket \lambda z \phi \rrbracket_{M, g, c e}^{x}=\left\{d \mid M, g[z / d], c e \models^{x} \phi\right\}$

(For the interpretation of quantifiers I will have to complicate matters a bit further, cf., below, but for the moment this will do.) A $\lambda$-term $\lambda x \phi$ is associated with a presupposed set of individuals $\llbracket \lambda z \phi \rrbracket_{M, g, c e}^{p}$, a contributed set of individuals $\llbracket \lambda z \phi \rrbracket_{M, g, c e}^{c}$, and an asserted set $\llbracket \lambda z \phi \rrbracket_{M, g, c e}^{a}$. The interpretation of terms can now be defined:

\section{Definition 3 (Interpretation of terms)}

- $\llbracket M A R Y \rrbracket_{M, g, d e}^{p}=\{Q \mid d=M(m) \& d \in Q\}$ $\llbracket M A R Y \rrbracket_{M, g, d e}^{c}=\{Q \mid d \in Q\}=\llbracket M A R Y \rrbracket_{M, g, d e}^{a}$

- $\llbracket H E_{i} \rrbracket_{M, g, d e}^{p}=\left\{Q \mid d=e_{i} \& d \in Q\right\}$ $\llbracket H E_{i} \rrbracket_{M, g, d e}^{c}=\{Q \mid d \in Q\}=\llbracket H E_{i} \rrbracket_{M, g, d e}^{a}$

- $\llbracket \operatorname{SOME}(\pi) \rrbracket_{M, g, d c e}^{p}=\left\{Q \mid d \in \llbracket \pi \rrbracket_{M, g, c e}^{p} \& d \in Q\right\}$ $\llbracket \operatorname{SOME}(\pi) \rrbracket_{M, g, d c e}^{c}=\left\{Q \mid d \in \llbracket \pi \rrbracket_{M, g, c e}^{c \& a} \& d \in Q\right\}$ $\llbracket \operatorname{SOME}(\pi) \rrbracket_{M, g, d c e}^{a}=\{Q \mid d \in Q\}$

- $\llbracket T H E(\pi) \rrbracket_{M, g, d c e}^{p}=\left\{Q \mid\{d\}=\llbracket \pi \rrbracket_{M, g, c e} \& d \in Q\right\}$ $\llbracket T H E(\pi) \rrbracket_{M, g, d c e}^{c}=\{Q \mid d \in Q\}=\llbracket T H E(\pi) \rrbracket_{M, g, d c e}^{a}$

- $M, g$, dace $\models^{x} T(\rho)$ iff $\llbracket \rho \rrbracket_{M, g, a c e}^{x} \in \llbracket T \rrbracket_{M, g, d c e}^{x}$ 
The interpretation of the name $M A R Y$ neatly illustrates the way in which terms are dealt with in this system. A use of the term presupposes a witness $d$ for Mary $\left(d=[m]_{M, g, e}=M(m)\right)$, which, in addition, satisfies the presuppositions of an associated verb phrase ( $Q$, which is abstracted over). A use of this term furthermore doesn't add anything to a contribution or assertion, except for the witness $d$ itself. So if "Mary" is combined with a verb phrase $\rho$, the presupposition is that the witness $d$ is Mary and that $d$ satisfies the presuppositions of $\rho$; the contribution is whatever $\rho$ contributes to $d$, and the assertion is whatever $\rho$ asserts about $d$. The interpretation of the other terms follows a similar pattern.

Pronouns come with the explicit presupposition that they are defined, and they only contribute their witness. ${ }^{10}$ Since indefinites $\operatorname{SOME}(\pi)$ are compound expressions, their interpretation is a bit more involved. They inherit the presuppositions of $\pi$, and they contribute their witness as an individual which is supposed to satisfy both the contributive and assertive interpretation of $\pi$.

Let us inspect two, related, examples. First example (11) with its associated logical translation, with obvious abbreviations:

(11) Jim offered Mary a cigar.

$$
J I(\lambda x M A(\lambda y S M(C G)(\lambda z O F x y z)))
$$

We find that $M, g, a b c \models^{p}$ (11) iff:

- $\llbracket \lambda x M A(\lambda y S M(C G)(\lambda z O F x y z)) \rrbracket_{M, g, b c}^{p} \in \llbracket J I \rrbracket_{M, g, a}^{p}$ iff

$$
\begin{aligned}
& a=M(j) \text { and } a \in \llbracket \lambda x M A(\lambda y S M(C G)(\lambda z O F x y z)) \rrbracket_{M, g, b c}^{p} \text { iff } \\
& a=M(j) \text { and } M, g[x / a], b c \models^{p} M A(\lambda y S M(C G)(\lambda z O F x y z)) \text { iff } \\
& a=M(j) \text { and } \llbracket \lambda y S M(C G)(\lambda z O F x y z) \rrbracket_{M, g[x / a], c}^{p} \in \llbracket M A \rrbracket_{M, g[x / a], b}^{p} \text { iff } \\
& a=M(j), b=M(m) \text { and } M, g[x / a][y / b], c \models^{p} S M(C G)(\lambda z O F x y z)
\end{aligned}
$$

Since the last condition is trivially satisfied, the presupposition of (11) is that $a=M(j)$ and $b=M(m)$. In a similar vein we find that $M, g, a b c \models^{c}$ (11) iff:

- $\llbracket \lambda x M A(\lambda y S M(C G)(\lambda z O F x y z)) \rrbracket_{M, g, b c}^{c} \in \llbracket J I \rrbracket_{M, g, a}^{c}$ iff

$$
\begin{aligned}
& a \in \llbracket \lambda x M A(\lambda y S M(C G)(\lambda z O F x y z)) \rrbracket_{M, g, b c}^{c} \text { iff } \\
& M, g[x / a], b c \models^{c} M A(\lambda y S M(C G)(\lambda z O F x y z)) \text { iff } \\
& M, g[x / a][y / b], c \models^{c} \operatorname{SM}(C G)(\lambda z O F x y z) \text { iff } \\
& c \in M(C G) \text { and } c \in \llbracket \lambda z O F x y z \rrbracket_{M, g[x / a][y / b]}^{c} \text { iff } c \in M(C G)
\end{aligned}
$$

Computing the assertoric part is even easier, since $M, g, a b c \models^{a}$ (11) iff:

\footnotetext{
${ }^{10}$ Notice the difference with the interpretation of pronouns in PLA. Here, and not in $P L A$, pronouns and proper names do contribute their witness as a new value to the sequence of witnesses. As a matter of fact, all noun phrases contribute a referent.
} 
- $\llbracket \lambda x M A(\lambda y S M(C G)(\lambda z O F x y z)) \rrbracket_{M, g, b c}^{a} \in \llbracket J I \rrbracket_{M, g, a}^{a}$ iff

$$
\begin{aligned}
& a \in \llbracket \lambda x M A(\lambda y S M(C G)(\lambda z O F x y z)) \rrbracket_{M, g, b c}^{a} \text { iff } \\
& M, g[x / a], b c \models^{a} M A(\lambda y S M(C G)(\lambda z O F x y z)) \text { iff } \\
& \llbracket \lambda y S M(C G)(\lambda z O F x y z)) \rrbracket_{M, g[x / a], c}^{a} \in \llbracket M A \rrbracket_{M, g[x / a], b}^{a} \text { iff } \\
& M, g[x / a][y / b], c \models^{a} S M(C G)(\lambda z O F x y z) \text { iff } \\
& c \in \llbracket \lambda z O F x y z \rrbracket_{M, g[x / a][y / b]}^{a} \text { iff } M, g[x / a][y / b][z / c], \models O F x y z
\end{aligned}
$$

that is iff $\langle a, b, c\rangle \in M(O F)$. All in all, relative to a seqeunce of witnesses $a b c$ example (11) is satisfied if it satisfies the presupposition that $a$ is Jim, that $b$ is Mary, if it contributes a cigar $c$, and the assertion that $a$ offered $c$ to $b$ is satisfied as well. Notice that these witnesses, as in $P L A$, remain there for subsequent anaphoric reference. Thus, a continuation with:

(12) She refused it.

$$
\mathrm{SHE}_{2}\left(\lambda y I T_{3}(\lambda z R E F y z)\right)
$$

relative to a sequence $e=b^{\prime} c^{\prime} a b c$ will presuppose that $b^{\prime}=(a b c)_{2}=b$ and that $c^{\prime}=(a b c)_{3}=c$ and asserts that $b^{\prime}=b$ refused $c^{\prime}=c$.

The interpretation of a definite $\operatorname{THE}(\pi)$ is fairly straightforward. It presupposes a witness $d$ which is the one and only individual which satisfies the presupposition, contribution and assertion expressed by $\pi$. Thus, relative to $d d^{\prime} e$, the daughter of some woman, or THE $(\lambda x S O M E(W O M A N)(\lambda y D T R x y))$, presupposes that $d$ is the one and only daughter of a woman $d^{\prime}$. It may have to be added here that the conditions figuring in the presupposition, contribution, and assertion of the terms, definite and indefinite, may vacilate between the three dimensions. The contribution of an indefinite can be turned into a presupposition, the presupposition of a definite into a contribution, and the contributions of both into an assertion, etc. For the moment the most important thing to observe is that we have some distribution of semantic material over the three dimensions, and that the conjunction of the distributed conditions equals their standard interpretation.

Let us now turn to really quantified constructions. Genuinely quantifying noun phrases are not just interpreted relative to possibly intended referents $d$ and sequences of witnesses, but to referent sets $D$ and sequences of witness functions, functionally dependent on the variables quantified over. In order to make this to work I have to introduce further notation conventions. First, if $f h$ is a sequence of (possibly functional) witnesses, $(f h)(d)$ is recursively short for $f(d) h(d)$, where $e(d)$ is $e$ if $e$ is a (non-functional) witness itself. Abstraction can now be generalized as follows:

- $\llbracket \lambda z \phi \rrbracket_{M, g, f h}^{x}=\left\{d \mid M, g[z / d],(f h)(d) \models^{x} \phi\right\}$

A further complication is that the interpretation of a common noun phrase $\lambda x \phi$ may fail to include all elements which as a value of $x$ satisfy $\phi$, viz., if the wrong witness or witness-function is chosen. For this reason I also employ the notation $! \lambda x \phi$ which gets interpreted as the maximal set for which we can find witnesses, and which generates a witness-function for that set: 
- $\llbracket ! \pi \rrbracket_{M, g, f h}=\left\{d \mid \exists c: d \in \llbracket \pi \rrbracket_{M, g, c(h(d))} \& f\right.$ is the function:

$$
\left.f\left(d^{\prime}\right)=c^{\prime} \text { iff } d^{\prime} \in \llbracket \pi \rrbracket_{M, g, c^{\prime}\left(h\left(d^{\prime}\right)\right)}\right\}
$$

Admitted, the !-notation is a bit cumbersome, but the definition of quantified expressions is now fairly easy:

\section{Definition 4 (Interpretation of quantified constructions)}

- $\llbracket D E T(\pi) \rrbracket_{M, g, D f h}^{p}=\left\{Q \mid \emptyset \neq D=\llbracket ! \pi \rrbracket_{M, g, f h} \subseteq Q\right\}$

$\llbracket D E T(\pi) \rrbracket_{M, g, D f h}^{c}=\{Q \mid D \subseteq Q\}$

$\llbracket \operatorname{DET}(\pi) \rrbracket_{M, g, D f h}^{a}=\{Q \mid Q \in[D E T](D)\}$

Before we turn to an illustration, a few observations are in order. With the above definition I have explicitly encoded the idea that determiners "presuppose their domain" in the sense that this (non-empty) set should be under discussion, contextually given, or what have you. Furthermore, all elements in the witness set are presupposed to satisfy the presuppositions of an associated verb phrase ( $Q$, which is abstracted over), and they also must allow a contribution from $Q$. The assertional contribution of a determiner is the standard one. This is significant, because it shows, in contrast with what has been suggested in the literature on discourse representation and dynamic semantics, that we do not have to tamper with the wellestablished findings from generalized quantifier theory. Finally, notice that at least two further amendations have to be made in the long run. First, a quantified structure (not downward monotonic) can be taken to contribute a witness set which consists of the intersection of the presupposed domain with the set denoted by the verb phrase. Second, downward monotonic quantifiers must be assumed to quantify away (existentially bind) the contribution of the terms they combine with.

Let us consider a simple example first:

Every boy offered every girl a cigar.

$$
A L L(\lambda x B O Y x)(\lambda x A L L(\lambda y G R L y)(\lambda y S M(\lambda z C G z)(\lambda z O F F x y z)))
$$

Let us abbreviate $\lambda x A L L(\lambda y G R L y)(\lambda y S M(\lambda z C G z)(\lambda z O F F x y z))$ as $V P_{1}$, and $\lambda y S M$ $(\lambda z C G z)(\lambda z O F F x y z)$ as $V P_{2}$. For $x=p, c$, or $a, M, g, D D^{\prime} f \models^{x}$ (13) iff $\llbracket V P_{1} \rrbracket_{M, g, D^{\prime} f}^{x} \in \llbracket A L L \rrbracket(\lambda x B O Y x) \rrbracket_{M, g, D}^{x}$. This presupposes that $D$ is the set of all boys plus whatever $V P_{1}$ presupposes; it contributes whatever $V P_{1}$ contributes, and it asserts that all elements of $D$ have the property asserted by $V P_{1}$. Spelling out $\llbracket V P_{1} \rrbracket_{M, g, D^{\prime} f}^{x}$, again for $x=p, c$, or $a$, this turns out to be $\{d \mid M$, $\left.g[x / d], D^{\prime}(f(d)) \models^{x} A L L(\lambda y G R L y)\left(V P_{2}\right)\right\}$ which is $\left\{d \mid \llbracket V P_{2} \rrbracket_{M, g[x / d], f(d)}^{x} \in \llbracket A L L\right.$ $\left.(\lambda y G R L y) \rrbracket_{M, g[x / d], D^{\prime}}^{x}\right\}$. Relative to any value $d$ for $x$, this presupposes $D^{\prime}$ to be the set of all girls, and this is, thus, automatically a presupposition of (13) as a whole ${ }^{11}$; it contributes what $V P_{2}$ contributes relative to any value $d$ for $x$, and it asserts whatever $V P_{2}$ asserts about all girls, relative to $d$. Now spelling out $\llbracket V P_{2} \rrbracket_{M, g[x / d], f(d)}^{x}$, again for $x=p, c$, or $a$, this turns out to be $\left\{d^{\prime} \mid M, g[x / d]\left[y / d^{\prime}\right],\left(f(d)\left(d^{\prime}\right)\right) \models^{x} S M(\lambda z C G z)\right.$

\footnotetext{
${ }^{11}$ I could have defined $D^{\prime}$ functionally, for possibly different values $d$ of $x$, but this would be redundant as it generates a constant function always yielding the set of girls as a value.
} 
$(\lambda z O F F x y z)\}$. The embedded formula comes with no presuppositions, it contributes $f(d)\left(d^{\prime}\right)$ as a cigar-witness $c$, and it asserts that the current value of $x$ (viz., $d$ ) offered $c$ to the value of $y$ (viz., $\left.d^{\prime}\right)$. Now we can collect the results. The sequence $D D^{\prime} f$ satisfies (13) if $D$ is the presupposed set of boys, $D^{\prime}$ the presupposed set of girls, $f$ a contributed function from boys to a function from girls to cigars, and given this it asserts that every boy $d \in D$ offered a cigar $f(d)\left(d^{\prime}\right)$ to any girl $d^{\prime} \in D^{\prime}$. Notice that the combined meaning is indeed what we would have wanted to have in the first place, but also that it is obtained by a system of interpretation distributed over various dimensions (three, in this case); notice, too, that both the backward looking behavior is accounted for (the presupposed sets $D$ and $D^{\prime}$ ) but also the forward looking behavior, in the sense that our witness function may come back to the boys and girls and be used to say more, for each boy and girl, about the cigar the one offered to the other.

The last point may serve to explain donkey-type dependencies, as we find in (14):

(14) Every farmer who owns a donkey beats it.

Here it turns out to be claimed that every farmer beats the donkey the farmer owns. The system as well accounts for subsequent (functional) anaphoric take-up, as in (15) (after an example from Gabriel Sandu)

(15) Every boy has a gun, but hardly any boy ever uses it.

The example can be used to claim that hardly any boy uses the gun the boy owns. Let us inspect one example in detail. Consider:

(16) Most men who sent a present to Curt sent a different 2 present to Amelia.

This sentence has the form $\operatorname{MOST}(\pi)(\rho)$ with:

- $\pi:=\lambda x M A N x \wedge C U R T(\lambda y S O M E(\lambda z P R E S z)(\lambda z S E N D x y z))$

- $\rho:=\lambda x A M E L\left(\lambda y \operatorname{SOME}\left(\lambda z z \neq \mathrm{p}_{2} \wedge \operatorname{PRESz}\right)(\lambda z \operatorname{SENDxyz})\right)$

These two expressions are interpreted as follows:

- $\llbracket \pi \rrbracket_{M, g, c p}^{p}=\{d \mid c=M(c u)\}$

$\llbracket \pi \rrbracket_{M, g, c p}^{c}=\{d \mid p(d) \in M(P R E S)\}$

$\llbracket \pi \rrbracket_{M, g, c p}^{a}=\{d \mid d \in M(M A N) \&\langle d, c, p(d)\rangle \in M(S E N D)\}$

- $\llbracket \rho \rrbracket_{M, g, a q e}^{p}=\{d \mid a=M(a m)\}$

$\llbracket \rho \rrbracket_{M, g, a q e}^{c}=\left\{d \mid q(d) \neq e_{2}(d) \& q(d) \in M(P R E S)\right\}$

$\llbracket \rho \rrbracket_{M, g, a q e}^{a, g}=\{d \mid\langle d, a, q(d)\rangle \in M(S E N D)\}$

and the whole structure has the following satisfaction conditions:

- $M, g, \operatorname{Daqcp} \models^{x} \operatorname{MOST}(\pi)(\rho) \quad$ iff $\llbracket \rho \rrbracket_{M, g, a q c p}^{x} \in \llbracket \operatorname{MOST}(\pi) \rrbracket_{M, g, D c p}^{x}$

Inspecting the above definition the reader may verify that this presupposes that:

- $\emptyset \neq D=\llbracket ! \pi \rrbracket_{M, g, c p} \subseteq \llbracket \rho \rrbracket_{a q c p}^{p}$ 
which is to say that $c$ is Curt, $a$ is Amelia, $D$ is the non-empty set of men $d$ who sent a present to $c$, and if any man $d$ sent any present to $c$ then $p(d)$ is that present. It is contributed that:

- $D \subseteq \llbracket \rho \rrbracket_{a q c p}^{c}$

which is to say that $q(d)$ is a present different from $p(d)$ (for all $d \in D$ ). Notice that the given presupposition and contribution are independent of the determiner chosen. Of course, the assertion is not independent:

- $[\operatorname{MOST}](D)\left(\llbracket \rho \rrbracket_{a q c p}^{a}\right)$

which is to say that for most $d \in D: d$ sent $q(d)$ to $a$.

I conclude this section with two more observations. First, the witness functions contributed by quantified structures can be taken up by anaphoric pronouns (as we see in, e.g., 15), that is, provided that the pronouns themselves are functionally dependent. Thus, the second sentence of (15) may come to mean that hardly any boy $d$ uses $g(d)$, a/the gun he owns. And after an utterance of the first sentence of (15) we can even make sense of:

\section{Sue uses it to chase foxes.}

provided our witness $s$ is a boy named Sue. Second, I have managed to keep our definitions relatively transparent by means of the uniqueness presupposition on witnesses contributed by a quantifier's restriction. Indeed, in order to account for all types of donkey sentences found in the literature, this presupposition may be too strong (see, e.g., Heim 1982; Heim 1990). However, although, of course, the presupposition can easily be relaxed, it might not be wise to do so. In (van Rooy 1997b; Geurts 2002a) both empirical and theoretical arguments are given in favour of a uniqueness presupposition. Discussing some experimental data concerning so-called 'strong' and 'weak' interpretations of donkey sentences, Geurts convincingly argues that what seem to be different readings are not different readings after all. What Geurts calls the "unwary" informant's interpretation of these sentences is indeed built on a uniqueness presupposition like the one proposed here. In case the presupposition is evidently violated, the informant faces what Geurts calls an "interpretative crisis', , which she has to resolve by additional means. ${ }^{12}$

\section{On pragmatic ambiguities and scope islands}

In the preceding section I have presented a three-dimensional architecture which can be used to model the various kinds of contributions certain expressions may make to interpretation. In a sense it is, at the same time, a semantic implementation of the proposals made by Kamp, van der Sandt, and Geurts, as well as a deconstruction of

\footnotetext{
12 Geurts observes that there may be various strategies towards a solution of this crisis, which may depend on the specific examples and on the type of informant, and which may yield different evaluations of the sentences. This indeed explains why our intuitions on the donkey sentences at issue are so 'nebulous' (as Heim 1982 deemed them), and as Geurts' experiments confirm.
} 
the notion of meaning endorsed by advocates of Montague grammar, and, I think, an improvement upon both.

Both the linguistic and the philosophical literature on presupposition from the seventies contain a number of highlights which are both illuminating and disappointing. A great number of (conceptual) tools and intuitively motivated analyses have been offered, which have an almost irrefutable theoretical appeal. Classic is the work of Robert Stalnaker, Lauri Karttunen, and Gerald Gazdar, and, not so classical, but equally important, that of Stanley Peters (Peters 1979). These pioneers have detected some principled ways in which presuppositions may behave in natural language, but they also had to agree that "presupposition", if any general use of the term is viable at all, does not behave that systematically. It is remarkable indeed that, first, Stalnaker had to systematically incorporate "pragmatic' remedies to account for apparent cases of presupposition failure (Stalnaker 1978), second, that Karttunen and Peters ended up writing a "Requiem for Presuppositions"' (Karttunen and Peters 1977) and, third, Gazdar had to plea for a benevolent "euthanasia", (Gazdar 1979) on the most important research tradition emerging from that decade, that of Karttunen and Peters.

The main conclusion which can be drawn from all of these efforts, I think, is twofold (and not generally accepted by the way). First, the behavior of presuppositions, if any such things exist, is subject to pragmatic principles, and, second, presuppositions, as well as other components of meaning, are entities in their own right. For those who know how satisfaction theories of presupposition work, no matter how appealing these theories may be, they simply don't work empirically, as Gazdar, van der Sandt, and Geurts, among many others, have shown in great detail. ${ }^{13}$ Willingly or unwillingly, van der Sandt has developed his theory of presupposition in accordance with these two conclusions in the procedural framework of DRT; quite rightly, this theory has gained a lot of empirical support; but even so, it hasn't answered the question (or never even intended to think of the question at all) what presuppositions are, besides things that have to be 'handled', 'bound' or 'resolved'. I will come back to this issue in the final section of this paper.

As a matter of fact, these points have shown up in a debate about specific and non-specific reference, and that of speaker's reference and semantic reference, which constituted a lively issue in the 70s and which, surprisingly maybe, seemed to have developed independent of the previous issue. Some of the main points from this debate, with main antagonists (Donnellan 1966) and (Kripke 1979), focus on

\footnotetext{
13 Notwithstanding their extreme initial appeal, rigid satisfaction and update semantic accounts are at odds with both of the previous conclusions. Logical and linguistically oriented approaches to presupposition, which revived in many dynamic semantic approaches in the nineties (among many others, Beaver 1995; van Eijck 1994; Heim 1992; Visser 1994; Zeevat 1992), face the dilemma of either assigning (18) a too strict, rigid, interpretation:
}

(18) Sid didn't invite the president of Trans-Danubia to the exhibition.

or rendering it semantically multiply ambiguous. 
the following two examples, which can be seen to fit neatly in our architecture. ${ }^{14}$ The first one is from (Kripke 1979):

Jones is raking the leaves.

I agree with almost everybody that this sentence has only one interpretation: that the person named Jones is doing what he is said to do: raking the leaves. But there are some subleties when an utterance of this sentence is actually encountered. The addressee may, for instance, notice it is an assertion about some prominent individual who is not Jones, but Smith, and react:

It is Smith, not Jones, who is raking the leaves.

thereby leaving the assertion that he (Smith) is raking the leaves unchallenged. But the addressee might as well take an utterance of (19) to be about Jones, replying:

If you say so. I only see Smith raking the leaves.

In our architecture (19) can be analyzed as JONES( $\lambda x R A K I N G x)$, which receives its standard, classical, interpretation. However, once one interprets the sentence, the interpreter (the hearer or an external observer) may notice that the sentence is uttered with a witness $d$ in mind who is actually not Jones but Smith. Now our multidimensional split pays off: under the interpretation $\llbracket J O N E S(\lambda x R A K I N G x) \rrbracket_{M, g, d}$, where $d=M(\mathrm{sm})$ and $d \neq M(j o)$, we find that the presupposition that $d$ is Jones is not satisfied, even though something true is asserted about $d$, viz., that he is raking the leaves. As a matter of fact, this is typically the interpretation that gives rise to reply (20). Alternatively, a reply like (21) is appropriate if one understands the term jo as it ought to be, namely as the individual who actually is Jones. In Kripke's terminology, the first would be a case of speaker's reference, and the second one of semantic reference. Notice that both interpretations neatly fit in our interpretational architecture.

An analysis of Donnellan's famous case of the martini drinker can be cast in an analogous fashion. On a social occasion, someone says, nodding at a certain person at the other side of the room:

(22) The man drinking a martini over there just sailed around the world.

There may be a man drinking a martini over there who hasn't sailed around the world, even though the man the speaker has in mind did. This is a case of presupposition failure, but even so we are right to argue, like Donnellan, and as Kripke agrees, that something true has been said. This is the case when we upload our interpretation with the obvious observation that the witness is the intended speaker's referent. We can also be nerdish, and reply: "No, there is one man drinking a martini over there, you cannot see even him, but he did not sail around the world. (You may have intended to refer to the guy holding a glass of water, but this does not verify your statement that (22)).' Again, these findings, both consistent with

\footnotetext{
${ }^{14}$ It may be noticed that examples such as these have previously been denied of any logical interest by Geach (1962).
} 
Donnellan's and those of Kripke, can be neatly formulated in our architecture. And I want to emphasize here that it really is due to the separation of different aspects of interpretation, which gives us the freedom to arrive at different interpretations without postulating a structural (syntactic or semantic) ambiguity. ${ }^{15}$

The previous observations indicate some of the flexibility in how we can understand utterances which are built up straightforwardly from components which have been assigned definite meanings, distributed over three dimensions, that is. Interestingly, this also brings to bear on an analysis of indefinite terms in so-called scope islands, often also deemed pragmatic, but equally well not integrated within a formal account of the pragmatics involved. In the remainder of this section I want to argue that the seemingly deviant behavior of indefinites is not deviant at all, that it can be expected in the present architecture, and that the architecture indeed provides the formal tools to state the required interpretations. (Something which cannot be said of a few of its predecessors.)

There is a whole range of literature on this subject, starting with (Cooper 1979; Fodor and Sag 1982) and with quite a few recent contributions among which, e.g., (Abusch 1994; Reinhart 1997; Winter 1997; Kratzer 1998; Matthewson 1999). Most of the literature is concerned with the following challenge. In the linguistic canon so-called 'scope islands' have been identified, certain linguistic environments from which quantified expressions and wh-phrases cannot 'escape', by raising or movement. Examples of scope islands are for instance relative clauses, if-clauses of conditional sentences, and other subordinate clauses like those headed by "because'. Definite and indefinite noun phrases, however, do seem to do what the canon forbids them to do. Sentences with (in-)definite noun phrases in scope islands receive interpretations which can be given an appropriate paraphrase by moving the (in-)definite to the sentence's initial position and filling in its original position with a (bound) pronoun. Consider, for instance:

(23) If every student comes to the party, Max will have a problem.

(24) Every student is such that if he comes to the party, Max will have a problem.

Both sentences have a particularly legitimate reading, but (24) is no paraphrase of any reading of (23). (For notice that it is equivalent with "If any student comes to the party, Max will have a problem,', which is no reading of (23).) The mentioned 'scope island constraint' accounts for this. But now consider the following example from Reinhart:

(25) If we invite a certain philosopher Max will be offended, but do you remember who?

There is a certain philosopher such that if we invite him, Max will be offended.

\footnotetext{
15 Actually, one can make more sophisticated distinctions. That is, one may agree that the intended witness over there sailed around the world, but disagree that what he is holding (the witness for 'martini') is a martini: it is just plain water. Equally possible in Amsterdam, but less likely in general, consists in agreeing that the witness is drinking a martini and sailed around the world, but that it is a woman, not a man.
} 
The reformulation (26) in which the indefinite gains wide scope seems to be an appropriate paraphrase of a reading of the first sentence of (25), indeed the only sensible reading given the continuation with "do you remember who?'. (Fodor and Sag 1982) have solved this problem and saved the scope constraint by postulating an ambiguity. Indefinites can be quantificational, and these indefinites are subject to the scope constraint; but indefinites can also be referential, and since referential expressions are 'scope-less', or 'scopally transparent', the scope island constraint does not apply to them. Fodor and Sag's solution has been challenged, vehemently and repeatedly, on two scores. In the first place it is prima facie suspect to posit ambiguities to solve syntactic-semantic problems, and I as well think that such an aversion against this practice, an aversion which goes back at least to (Grice 1975, “'Modified Occam's Razor'), is wholesome indeed. In the second place people soon came up with a whole range of examples which show that a two-way ambiguity could never suffice, and which suggest that a completely different account should be given (Farkas 1981; Abusch 1994; Reinhart 1997). The following example is due to Dorit Abusch:

(27) Every one of them moved to Stuttgart because a woman lived there.

There is a most natural interpretation of this example according to which for every person among the intriguing 'them' there was a woman who lived in Stuttgart, and whose living in Stuttgart made up the reason for that person to move to Stuttgart. Notice that, upon this paraphrase, the woman seems to have escaped the 'because'island, even though there is not necessarily only one woman involved. Thus, first, the interpretation given is different from Fodor and Sag's quantificational interpretation, upon which the reason for everybody to move to Stuttgart was that Stuttgart is not for $100 \%$ inhabited by males, quite an unlikely reason; but, second, it is also different from the referential interpretation upon which the reason for everybody to move to Stuttgart was that, e.g., Dorit Abusch herself lived there.

Faced with examples like that of Abusch and others, some authors have resorted to the use of a so-called 'choice function' analysis of indefinite noun phrases, ${ }^{16}$ extended with a free and fancy existential closure over the relevant choice function variables. For reasons which I do not want to go into here, such an analysis faces its own complications and will, if viable at all, at best be redundant. (For some discussion, see Schlenker 1999; Bendefarkas and Kamp 2001; Dekker 2004b; Jäger 2002.)

In this paper I therefore want to keep the gist of Fodor and Sag's analysis and save the scope constraint but without postulating any ambiguity. The various interpretations that have been labeled 'referential' or 'wide scope', and those that have been labeled 'intermediate', can be seen to derive from independently motivated pragmatic principles. As a matter of fact, such an approach is not at all new, as it may already have been implicit in Fodor and Sag's own analysis, as it has been anticipated in (Kratzer 1998), and as similar ideas have very recently been advocated by (Bende-Farkas and Kamp 2001; Geurts 2002b; Dekker 2004b; Breheny 2006; Jäger 2002).

${ }_{16}$ Dating back to the epsilon operator of Hilbert and Bernays, and also employed, for different reasons, in, e.g., (Meyer-Viol 1995; Egli and Heusinger 1995), among others, in the analysis of indefinites. 
The basic idea I want pursue is simple: indefinites, like definites, have other than purely assertoric aspects, and if structural syntactic and semantic properties condemn their assertoric force to live in a scope island, the other aspects are unaffected. More specifically, the semantic or assertional contribution of an (in-)definite noun phrase, a referent or referent set, is bound to the scope islands where these terms are dropped. But (in-)definites have access to other (pragmatic) dimensions, and there they may freely interact with other surface material and contextually supplied information. The fact that the use of an (in-)definite comes with an intended witness or referent can be taken to be pragmatic, and therefore be independent from its semantics - with one proviso though, viz., that the presupposition or contribution of (in-)definites may get bound or get functionally dependent upon other material.

Let us inspect example (27) in a suitably simplified form. Consider (28), with its reduced logical form (29):

(28) Everybody came because a woman came.

$$
A L L(\lambda x B E C(S O M(W O M)(C A M))(C A M x))
$$

I assume an over-simplified, because extensional, analysis of 'because', because I want to focus on the structural aspects of the interpretation of (29). The 'basic' interpretation of the main constituents can then be rendered as follows:

- $M, g, D f h \models^{x} A L L(\rho)$ iff $D \subseteq \llbracket \rho \rrbracket_{M, g, f h}^{x}$

- $M, g$, pqace $\models^{p} B E C(\phi)(\psi)$ iff $M, g, c e \models \phi$ and $M, g$, ace $\models \psi$

$M, g$, paqce $\models^{c} \operatorname{BEC}(\phi)(\psi)$ iff $q=\llbracket \phi \rrbracket_{M, g, c e}^{a}$ and $p=\llbracket \psi \rrbracket_{M, g, a c e}^{a}$

$M, g$, pqace $\models^{a} B E C(\phi)(\psi)$ iff $\langle p, q\rangle \in M(B E C)$

- $M, g, d e \models^{p} \operatorname{SOM}(W O M)(C A M)$

$M, g, d e \models^{c} \operatorname{SOM}(W O M)(C A M)$ iff $d \in M(W O M)$

$M, g, d e \models^{a} \operatorname{SOM}(W O M)(C A M)$ iff $d \in M(C A M)$

- $M, g$, de $\models^{p} C A M x$

$M, g, d e \models^{c} C A M x$

$M, g, d e \models{ }^{c} C A M x$ iff $g(x) \in M(C A M)$

Taking $B E C(S O M(W O M)(C A M))(C A M x)$ as the 'logical form' of the clause " $x$ came because a woman came" it can be read in one of two ways. The contribution of $\operatorname{SOM}(W O M)(C A M)$ can be bound under the $B E C$-operator, which yields the result that it is presupposed that some woman came and that $x$ came; it contributes the propositions or facts $p$ and $q$, that some woman came and that $x$ came, respectively; and asserts that $q$ is because of $p$. The three dimensions of meaning are abstracted over in $x$, also the propositional witnesses $p$ and $q$, and the abstraction is bound by the quantifier $A L L$. As a result, sentence (28) can be interpreted so that it presupposes that at least one woman came and that all individuals in $D$ came; so that it contributes propositional functions assigning each individual in $D$ the proposition that that individual comes and the proposition that some woman comes, respectively; and so that it asserts that, for each individual in $D$, the first proposition was because of the latter. That is, for each individual $d \in D$, the fact that at least one woman came 'caused' him to come as well. 
The contribution of $S O M(W O M)(C A M)$ can project through the $B E C$-operator on an alternative interpretation, which yields the result that it presupposes that some intended woman $d$ came and that $x$ came it contributes the propositions or facts $p$ and $q$, that $d$ came and that $x$ came, respectively; and it asserts that $q$ is because of $p$. The three dimensions of meaning are again abstracted over in $x$, not only the propositional witnesses $p$ and $q$, but this time the individual $d$ as well, and the abstractions are bound by the quantifier $A L L$. As a result, sentence (28) presupposes an individual function $f$ which assigns each individual in $D$ a woman who comes whereas that individual itself comes as well; it contributes two propositional functions assigning each individual in $D$ the proposition that the proposition that the woman associated with that individual comes and that individual comes, respectively; and it asserts that, for each individual in $D$, the second proposition was because of the first. That is, for each individual $d \in D$, there is some woman $f(d)$ such that the fact that $f(d)$ came 'caused' $d$ to come as well. Indeed, this corresponds to the interpretation obtained on the so-called intermediate reading of the indefinite. Notice that the indefinite noun phrase not only retains the position which it was assigned in the logical form in (29) under BEC, but also semantically its assertoric force remains under the scope of that operator. For any individual $d \in D$, the indefinite supplies a witness $f(d)$ at the assertoric level, in the scope island, and to the effect that the (presupposed) fact that $f(d)$ came is asserted to have caused $d$ 's coming.

It is easy to derive a truly specific interpretation from the intermediate one. If we take, as a witness for the indefinite 'a woman', a constant function from individuals in $D$ to one and the same woman $b$, it is presupposed that $b$ is a woman who came and that all $D$ came, the propositional (functional) witnesses $p$ and $q$ are contributed, and it is asserted that, for each $d \in D$, the fact $p^{\prime}(d)$ that $d$ came was because of the fact $q^{\prime}(d)$ that $b$ came. Again, syntactically, the indefinite has remained in place, and also at the assertoric level it has delivered its assertoric contribution, the witness $b$, in the scope island. ${ }^{17}$

A lot of dust has been raised about the deemed escapist behavior of indefinites in scope islands. I hope the preceding discussion has served to soothe matters a bit. For one thing, indefinite noun phrases behave the same, there, like other terms, such as proper names and definite noun phrases. Indefinites deliver their assertoric contribution, a witness, to the interpretation of the scope island which syntax and semantics has condemned them to live in. The fact that they have access to other dimensions of interpretation, where they may chase their witnesses, does not contradict this hard, syntactic constraint. Interestingly, very much the same can be said about genuinely quantified noun phrases. In section (3) binary determiners have been proposed to assert a relation between sets, and this is indeed something which cannot be lifted from scope islands. But determiners, as well, have their own dimensions of interpretation. It does not take any great effort to see that their domain presuppositions don't get constrained by any island configurations. Consider:

\footnotetext{
${ }^{17}$ As one of the reviewers remarked, it is easier to get this specific interpretation, and it remains unclear why this would be so on the approach presented. I have no real answer to this question. I could say, with a lot of hand-waving, that the specific interpretation is less costly, cognitively speaking, but I would agree this is not a very satisfactory answer.
} 
(30) If a boy goes to a party because he thinks most girls in his class come too, he is disappointed, of course, when they don't show up.

It doesn't matter, here, whether 'they' stands for the girls in a boy's class, or for most of them. What matters is that they are dependent on a boy, or on what class he is in, and that this dependence is not asserted but contributed by the construction 'most girls in his class' on the island under 'because'. Thus, although I do not want to deny that the assertoric contribution of 'most' is tied to the clause headed by 'because', its presupposition is not bound in that way, and in this sense the quantified noun phrase 'most girls in his class' behaves just like terms do. Its assertoric value is island bound, but its contribution or presupposition, of course, is not.

In sum, acknowledging various dimensions of interpretation is wholesome in two respects. First, it allows us keep to the scope island constraint, without any modifications. Second, it allows us to do away with putative counterexamples to that constraint, without the need to invent an ad hoc semantics for a category of terms which allow scope island constraint violating paraphrases. Upon reflection, these terms don't violate any scope island constraints, and they pattern well with all other noun phrases. Their cross-dimensional interpretation is independently and crosscategorially motivated.

\section{Discussion}

This is not the first paper to revive a multi-dimensional architecture of interpretation. Recently, Robert van Rooij has presented a modal multi-dimensional approach to presupposition, ${ }^{18}$ and Christopher Potts (Potts 2005) has argued, at length and in detail, for one or many dimensions of meaning separate from that of primary semantic content. Potts has done so in a more radical way than I do, and with a significantly larger empirical scope. A systematic evaluation of his results and those of mine will have to await another occasion though. In this section I briefly compare my approach with that of van Rooij, and suggest a way of multi-dimensionally doing things in the representational format of Discourse Representation Theory $(D R T)$. I will conclude with some contemplations on the consequences of the approach advocated here in the contextualist debate.

Robert van Rooij presents a literal implementation of Robert Stalnaker's idea that presupposition is in fact a propositional attitude. The idea is that on specific occasions speakers presuppose certain information to be commonly known, for instance information that has been exchanged before; well-regimented discourse is supposed to proceed on these terms. Thus, we can say "The president of the United States visited Nepal this weekend.' and we don't need to say "The United States has a president, one, that is, and that guy visited Nepal this weekend.' Taking presupposition to be a propositional act or attitude naturally invites a modal analysis of the subject, and this is what van Rooij actually presents. Such an approach naturally raises some standard question from modal logic. Do people always

\footnotetext{
${ }_{18}$ The paper was published after he has read a previous version of the present paper.
} 
presuppose every logical truth? Do people always presuppose that they presuppose what they presuppose? And if they do not presuppose something, do they presuppose they don't? If one pursues a modal analysis, these are the kind of questions that have to be answered, but they don't seem to be crucial to the issue. The nice thing about modal logic is that it has put an end to speculative early twentieth century discussions about modalities and, for instance, related them to intuitive properties of frames. When applied to the subject of presupposition, however, it only seems to raise more speculation rather than insight.

Van Rooij claims to endorse a two-dimensional theory of meaning. As we have seen above, the bite of a two-dimensional theory, which sets it apart from a three-valued logic or a satisfaction theory of presupposition, is the fact that something true can be asserted even if one's presuppositions may fail to hold. Van Rooij's system, however, only reasons about three options: a sentence can be defined and true, it can be defined and false, and it can be undefined and have a 'place-holder'. This might be a point of notational convenience, but it really goes deeper: "Although I use a four-dimensional logic, I am not explicit about when a sentence is true or false, although its presupposition is not satisfied." (van Rooij 2005, p. 284).

A more substantial point is this. While I think Karttunen and Peters' 'binding problem' really is a first order phenomenon, and while most if not all examples of modal subordination in the literature are first order as well, van Rooij's solution is cast, basically, in a propositional system, that is, in zero order predicate logic. Notice that, if indeed a modal first order analysis is pursued, one should also take a stand on the issues of rigidity and cross-world identity, two subjects which are not without pitfalls, and which, again, don't appear to be raised by the phenomenon of presupposition as such.

In this paper I have shown how to go about if one wants to conservatively extend a fully typed Montague grammar in various dimensions. For this, I haven't had the need to invoke a modal framework raising questions which weren't there in the first place. When we consider possible representational formulations of the present architecture, similar concerns play up. Presuppositions can and have been neatly dealt with in the representational format of $D R T$, and as such don't require any modalities. Discourse representation structures may give you all you need possible worlds for. (See Alberti 2000 for a radical version of this position.) But then again, how much of the representational structure is actually relevant? And how, eventually, do we get at the intended interpretation, which, after all, relates to the real individuals and events which we tend or intend to be speaking about?

The previous point also brings up the issue that may have tantalized the reader from the start of this paper, with good reason by the way. The point can be made very succinctly in the form of a quasi-question "Why not discourse representation theory?" and my reply is a quasi-assertion: "Why not, indeed?' Certainly the representational format of $D R T$ may be much more transparent and elucidating for the working student. For, for instance, a three-dimensional interpretation of (31) can be most perspicuously rendered by means of (32): 
George chased a husky.

\begin{tabular}{|c|l|l|}
\hline$x$ & $y$ & \\
\hline $\operatorname{george}(x)$ & $\operatorname{husky}(y)$ & $\operatorname{chase}(x, y)$ \\
\hline
\end{tabular}

In the architecture proposed in this paper, the example is supposed to presuppose George, to contribute a husky, and to assert that the first chased the second. As a matter of fact, a proposal along these lines has been developed by Bart Geurts and Emar Maier. Having come to this point I cannot but agree that this is the most convenient way to proceed, but I want to emphasize the qualification "having come to this point." All by itself, (32) is a picture without an interpretation. Why wouldn't (31) mean what we otherwise express as "The oldest Eskimo has discovered Gibraltar.' Of course, this is because we assume $D R S$ s to have an intuitively likely interpretation. One may argue that the present paper actually defines such an interpretation.

The current situation is, I believe, entirely similar to the one which Hans Kamp originally has put us in. Original $D R T$ was and is extremely practical for the working student. Too practical maybe, because it hadn't been stated from the outset what are the rules of the game. If we have representations at our disposal, we can manipulate them at will. Only if they are clearly associated with intuitive interpretations, we can make claims about what are sensible manipulations. For me personally, the very definition of dynamic predicate logics, however infelicitous in certain respects, constituted the major reason of accepting $D R T$ as a paradigm, because I could see $D R T$ had a sensible interpretation. With this paper I have worked in the opposite direction. I have first presented what I deem an intuitive interpretation, and one that properly allows one to use a $D R T$-style format at one's own benefit. I am definitely confident that a representational architecture, at least for the basic cases, is much more manageable than one along the lines presented here-not without this foundation though.

If cognitive scientists were to find out that discourse markers don't exist in our heads, I would have one more question to answer, not an easy one, but one at most. If, on the other hand, my theory would have said "such and so are the representations people actually employ in interpretation, and they attribute properties to discourse markers,' I would have had to redo my whole theory. Precisely for this reason I feel happy to have solid semantic ground for the proposals made here. ${ }^{19}$

Another principled discussion is relevant and I am hesitant to take it up. I have worked the multi-dimensional perspective to the extreme, and I was very happy to find out that such a division of labour between structured semantics and flexible pragmatics clears up the scope island discussion. Simplifying things a bit, I distinguish a semantic and a pragmatic dimension of interpretation, and they are governed by their own codes. Scope island constraints are to be studied by syntacticians, violations are to be prosecuted, but not denied, by pragmaticists, who, after all, are supposed to clear the bin. But can we sensibly maintain this division of labour?

\footnotetext{
19 This point has been made clear to me by Craige Roberts, pc.
} 
I am hesitant to take up this issue because it brings us into the contextualist debate. Let us first recollect some standard findings. I believe it is or should not be disputed that a term like 'bank' is ambiguous, and that there are syntactic and logical reasons to disambiguate the term. From the fact that Anke went to the river bank, and Laura to Barclays, we should not conclude the two went to the bank. There is good reason to say that, in logical form, we have two different lexical entries for 'bank', logically unrelated. Neither should we be happy to claim that "Every professor introduced every student to his class."' is true because some professors introduced every student to the professor's class, and the other ones introduced the students to their own, i.e., the student's, classes. We find good reason to assume that the term his is underspecified but it must refer to either the professors, or to the students, or to somebody else, but not to any mixture of these. Even though it is dubious practice, it is standard to assume that "every professor" and "every student" get an index, and that "his" selects one of these.

Now consider the following example:

\section{(33) Everyone visited a student in Stuttgart because a professor told him to} do so.

In principle, we can read the term 'a student' as an arbitrary student or as a specific one, and similarly for the term 'a professor.' So we gain two of at least four possible interpretations: "Everyone visited an arbitrary student because a specific professor told him to do so." "Everyone visited a specific student because an arbitrary professor told him to visit that student.' I don't believe there to be a likely interpretation according to which some visited some student whatsoever, and others did so because their professor told them to visit that student. The matter is subtle and intricate, but I believe it indicates that we have to assume that the (specific or nonspecific) interpretation of the indefinite terms has to be indicated on a structural level: like 'bank' and 'his' in the previous examples these different interpretations have to be disambiguated.

If the above reasoning is correct, and if our claim that the various readings of indefinites are a matter of pragmatics, then it means that pragmatic matters have to find their formulation on a structural level, that of logical form. Of course, this conclusion should not come as a surprise, given that ordinary English already allows for locutions like 'arbitrary' and 'specific', and that languages like, for instance, Spanish and Russian contain a whole repertoire of morphological devices to indicate how certain terms should be, pragmatically, interpreted. And for those on, what Stanley calls, the 'dark side' of the contextualist debate, this is of course the only thing one could have expected in the first place.

\section{Conclusion}

In this paper I have sketched and motivated an architecture for a flexible treatment of anaphora, presupposition and quantification. I have drawn from results from the recent literature, but the baseline has remained rather classical. On the issues of 
presupposition and quantification I have been conservative, and I have tried to implement the insights obtained in the seventies. My treatment of anaphoric relationships is of a more recent date, but equally conservative. It involves a proper, and minimal, extension of classical systems of interpretation. In no respect do I require, assume, or envisage a change in the standard Fregean, Wittgensteinian or Tarskian concept of meaning.

My hope is to have made clear that the old paradigms survive criticisms which are more often alluded to than argued for. What is more, I hope to have shown that they point to a perspective on the debate on scope islands which leads to a treatment which, unlike existing treatments, is not ad hoc. Yet, the costs may be substantial. Principally, I would have objected to allowing pragmatic considerations access to linguistic structure. At the present point, however, I don't see any other way to go about.

As one of the reviewers rightly pointed out, there need not be one single field of pragmatics. Like Stanley notes, Montague's and Kaplan's insights on 'formal pragmatics' can be said to properly belong to semantics if semantics is construed sufficiently context-sensitive. The methodological question that remains is how to decide what belongs to a compositional system of interpretation and what not, or, whether such a decision can be made in the first place.

Acknowledgements The work reported in this paper has been enabled by a grant from the Dutch Organization for Scientific Research (NWO) and it has substantially benefitted from comments by Bart Geurts, Jeroen Groenendijk, Pauline Jacobson, Barbara Partee, Craige Roberts, Floris Roelofsen, Igor Yanovich, Henk Zeevat, and an anonymous reviewer for L\&P, which is gratefully acknowledged.

Open Access This article is distributed under the terms of the Creative Commons Attribution Noncommercial License which permits any noncommercial use, distribution, and reproduction in any medium, provided the original author(s) and source are credited.

\section{References}

Abusch, D. (1994). The scope of indefinites. Natural Language Semantics, 2, 83-135.

Alberti, G. (2000). Lifelong discourse representation structures. In M. Poesio \& D. Traum (Eds.), Proceedings of Götalog 2000. Department of Linguistics, Göteborg.

Beaver, D. (1995). Presupposition and assertion in dynamic semantics. Ph.D. thesis, CCS, Edinburgh, Published in 2001 by CSLI Publications, Stanford.

Bende-Farkas, A., \& Kamp, H. (2001). Indefinites and binding: From specificity to incorporation. Technical report, IMS, Stuttgart.

Breheny, R. (2006). Non-specific specifics and the source of existential closure of exceptional-scope indefinites. University college working papers in linguistics, 18, University College London.

Cooper, R. (1979). The interpretation of pronouns. In F. Heny \& H. Schnelle (Eds.), Syntax and semantics (Vol. 10). New York: Academic Press.

Dekker, P. (1998). Speaker's reference, descriptions and information structure. Journal of Semantics, 15(4), 301-330.

Dekker, P. (2004a). Grounding dynamic semantics. In A. Bezuidenhout \& M. Reimer (Eds.), Descriptions and beyond: An interdisciplinary collection of essays on definite and indefinite descriptions and other related phenomena. Oxford: Oxford University Press.

Dekker, P. (2004b). The pragmatic dimension of indefinites. Research on Language and Computation, 2, 365-399.

Donnellan, K. (1966). Reference and definite descriptions. Philosophical Review, 75, 281-304. 
Egli, U., \& von Heusinger, K. (1995).The epsilon-operator and E-type pronouns. In U. Egli et al. (Eds.), Lexical knowledge in the organization of language (pp. 121-141). Amsterdam: Benjamins.

Farkas, D. (1981).Quantifier scope and syntactic islands. In R. A. Hendrick, C. S. Massek, \& M. F. Miller (Eds.), Papers from the Seventeenth Regional Meeting Chicago Linguistics Society (pp. 59-66). University of Chicago.

Fodor, J., \& Sag, I. (1982). Referential and quantificational indefinites. Linguistics and Philosophy, 5(3), 355-398.

Gazdar, G. (1979). Pragmatics, implicature, presupposition, and logical form. New York: Academic Press.

Geach, P. T. (1962). Reference and generality. An examination of some medieval and modern theories. Ithaca: Cornell University Press.

Geurts, B. (2002a). Donkey business. Linguistics and Philosophy, 25(2), 129-156.

Geurts, B. (2002b). Specific indefinites, presupposition and scope. In R. Bäuerle, U. Reyle, \& E. Zimmermann (Eds.), Presuppositions and discourse. Oxford: Elsevier.

Grice, H. (1975). Logic and conversation. In P. Cole \& J. L. Morgan (Eds.), Syntax and semantics, Vol III: Speech acts (pp. 41-58). New York: Academic Press.

Groenendijk, J., \& Stokhof, M. (1991). Dynamic predicate logic. Linguistics and Philosophy, 14(1), 39-100.

Heim, I. (1982). The semantics of definite and indefinite noun phrases. Ph.D. thesis, University of Massachusetts, Amherst, Published in 1988 by Garland, New York.

Heim, I. (1990). E-type pronouns and donkey anaphora. Linguistics and Philosophy, 13(2), 137-78.

Heim, I. (1992). Presupposition projection and the semantics of attitude verbs. Journal of Semantics, 9 , 183-221.

Jäger, G. (2002). Specific indefinites: Presupposition accommodation by existential closure. Konstanz: Talk given at Sinn und Bedeutung VII.

Kamp, H. (1990). Prolegomena to a structural theory of belief and other attitudes. In C. A. Anderson \& J. Owens (Eds.), Propositional attitudes (pp. 27-90). Stanford: CSLI.

Kamp, H., \& Reyle, U. (1993). From discourse to logic. Dordrecht: Kluwer.

Karttunen, L., \& Peters, S. (1975). Conventional implicature in montague grammar. In C. Cogen, H. Thompson, G. Turgood, K. Whistler, \& J. Wright (Eds.), Proceedings of the First Annual Meeting of the Berkeley Linguistics Society (pp. 266-278). University of California.

Karttunen, L., \& Peters, S. (1977). Requiem for presupposition. In K. J. Whistler, R. D. van Valin, C. Chiarello, J. J. Jaeger, M. Petruck, H. Thompson, R. Javkin, \& A. Woodbury (Eds.), Proceedings of the Third Annual Meeting of the Berkeley Linguistics Society (pp. 360-371). University of California.

Karttunen, L., \& Peters, S. (1979). Conventional implicature. In C.-K. Oh \& D. A. Dinneen (Eds.), Syntax and Semantics 11-Presupposition (pp. 1-56). New York: Academic Press.

Kratzer, A. (1998). Scope or pseudoscope? Are there wide-scope indefinites? In S. Rothstein (Ed.), Events in Grammar (pp. 163-196). Dordrecht: Kluwer.

Kripke, S. (1979). Speaker's reference and semantic reference. In P. A. French, T. E. Uehling, \& H. K. Wettstein (Eds.), Contemporary perspectives in the philosophy of language (Chaps. 6-27). Minneapolis: University of Minnesota Press.

Matthewson, L. (1999). On the interpretation of wide-scope indefinites. Natural Language Semantics, 7 , 79-134.

Meyer-Viol, W. (1995) Instantial Logic. Ph.D. thesis, OTS, Utrecht, ILLC Dissertation Series no. 1995-11.

Peters, S. (1979). A truth-functional formulation of Karttunen's account of presupposition. Synthese, 40, 301-316 (First appeared in S. F. Schmerling \& C. S. Smith (Eds.), Texas linguistic forum 6, University of Texas at Austin, 1977).

Potts, C. (2005). The logic of conventional implicature. Oxford: Oxford University Press.

Reinhart, T. (1997). Quantifier scope: How labor is divided between QR and choice functions. Linguistics and Philosophy, 20, 335-397.

Schlenker, P. (1999). A note on skolem functions and the scope of indefinites. Typoscript.

Stalnaker, R. (1978). Assertion. In P. Cole (Ed.), Syntax and semantics 9-Pragmatics (pp. 315-332). New York: Academic Press.

Stalnaker, R. (1998). On the representation of context. Journal of Logic, Language and Information, 7 , 3-19.

van Eijck, J. (1994). Presupposition failure: A comedy of errors. Formal Aspects of Computing, 6A, 766-787. 
van Rooij, R. (2005). A modal analysis of presupposition and modal subordination. Journal of Semantics, 22, 282-305.

van Rooy, R. (1997a). Attitudes and changing contexts. Ph.D. thesis, IMS, Stuttgart.

van Rooy, R. (1997b). Descriptive pronouns in dynamic semantics. In P. Dekker, M. Stokhof, \& Y. Venema (Eds.), Proceedings of the Eleventh Amsterdam Colloquium (pp. 265-270). ILLC, University of Amsterdam, Amsterdam.

Visser, A. (1994). Actions under presuppositions. In J. van Eijck \& A. Visser (Eds.), Logic and information flow. Cambridge, Mass: MIT Press.

Winter, Y. (1997). Choice functions and the scopal semantics of indefinites. Linguistics and Philosophy, 20, 399-467.

Zeevat, H. (1992). Presupposition and accommodation in update semantics. Journal of Semantics, 9(4), 379-412. 